\title{
Aplikasi Konsep Representatif terhadap Bentuk Bangunan Pusat Pengembangan Produk Kreatif di Menganti Kabupaten Gresik
}

\author{
Dwi Kresita Arjiyanti ${ }^{1}$, Ika Ratniarsih ${ }^{2}$, Dian P.E. Laksmiyanti ${ }^{3}$ \\ 1,2,3 Jurusan Arsitektur, Fakultas Teknik Sipil dan Perencanaan, Institut Teknologi Adhi Tama Surabaya \\ Email: ${ }^{1}$ kresitaarjiyanti@gmail.com
}

\begin{abstract}
Gresik Regency becomes the centre of business, trade, industry, and education in East Java Province. However, it has limited facilities such as craft and fashion to preserve the cultural heritage and to facilitate them for self- developing and connecting each other as well as becoming the icon of Gresik Regency. The object of plan is located on Morowudi Highway 185, Moro Putat Lor, Gresik Regency, East Java 61171. This design implements the theme of contemporary, according to L. Hilberseimer, Comtemporary Architects 2 (1964) "Contemporary Architecture is a style of a certain architectural flow in its era that reflects the freedom of work so that is displays something different, and is a new flow or a combination of several other arsitectural styles. Thus, through its unique shape, this creative building will remind creativity. The macro concept of object is representative to create a shape with recognizable characteristics and communicable ideas. The macro concept of representative land use can be noticed from the circulation and mass arrangement considering the existing conditions in the form of knowing the physical condition of the site, the environmental conditions at the site, the boundaries of the site, and the potential that exists at the site. whereas the macro concept of representative shape is carried out by combining the symmetrical shapes in the façade and roof pile. The macro concept of representative space occurs by adjusting and emphasizing the elements of pastel color and wood. Hence, the design of this object is beneficial for Gresik in creating a place facilitating creative producers to develop them selves and to connect each other among the sectors of creative products.
\end{abstract}

Keywords: Industry, Creative, Contemporary, Gresik

Abstrak. Kabupaten Gresik merupakan pusat bisnis, perdagangan, industri dan pendidikan yang ada di wilayah Jawa Timur. Dikarenakan kurangnya fasilitas untuk mengembangkan kreatifitas seperti kriya, fashion yang menjadi warisan budaya dan wadah bagi pelaku kreatif untuk mengembangkan diri dan saling terhubung antara satu sama lain, serta menjadi ikon di Kabupaten Gresik. Lokasi Objek rancangan yaitu berada di Jl. Raya Morowudi 185, Moro Putat Lor, Kabupaten Gresik, Jawa Timur 61171. Tema yang digunakan untuk rancangan ini adalah Kontemporer, Menurut L. Hilberseimer, Comtemporary Architects 2 (1964) "Arsitektur Kontemporer adalah suatu style aliran arsitektur terntentu pada eranya yang mencerminkan kebebasan berkarya sehingga menampilkan sesuatu yang berbeda, dan merupakan suatu aliran baru atau penggabungan dari beberapa gaya arsitektur lainnya, sehingga cocok untuk gedung kreatif yang mengingat kreatif menggunakan bentukan bangunan yang cukup unik. Konsep makro Representatif bertujuan untuk menciptakan sebuah rancangan yang memiliki karateristik mudah di kenal dan dapat mengkomunikasikan ide desain. Penerapan konsep makro representatif pada tatanan lahan yaitu sirkulasi dan penataan massa dengan mempertimbangkan eksisting yang berupa mengetahui kondisi fisik tapak, keadaan lingkungan pada tapak, batas-batas tapak, dan potensi yang ada pada tapak, Penerapan konsep makro representatif pada bentuk adalah penggabungan bentuk simetris pada fasad dan tumpukan pada atap. Penerapan konsep makro representatif pada ruang adalah penyesuaian dan penekanan unsur warna pastel dan unsur kayu. Manfaat dari Perancangan Objek ini yaitu agar Gresik memiliki sebuah wadah bagi para pelaku produksi kreatif untuk mengembangkan diri dan saling terhubung antara satu sama lain diantara sub sektor sub sektor produk-produk kreatif tersebut.

Kata kunci: Industri, Kreatif, Kontemporer, Gresik.

\section{Pendahuluan}

Pada rancangan ini untuk mengembangkan kreatifitas seperti kerajinan kriya guci, kriya rotan serta fashion bagi para pelaku kreatif agar mampu unggul dalam kualitas produk dan berdaya saing tinggi yang menjadi warisan budaya serta mampu menjadi wadah bagi para pelaku produksi kreatif 
untuk mengembangkan kreatifitasnya serta saling terhubung antara satu sama lain dan dapat menjadi ikon bangunan kreatif di Kabupaten Gresik.

Pada bangunan kreatif ini bentuk bangunan mengambil dari tema kontemporer itu sendiri dengan ciri khas yang mengandalkan bukaan yang lebar dan bentuk kontemporer sendiri tidak terikat oleh aturan lama dan terus berkembang sesuai zaman yang mewujudkan ragam gaya desain bangunan yang berasal dari berbagai pengaruh, sehingga cocok untuk gedung kreatif yang mengingat kreatif menggunakan bentukan bangunan yang cukup unik.

Berdasarkan permasalahan tersebut, gedung kreatif dirancang untuk mewadahi kebutuhan sekunder masyarakat sekaligus mendukung kreatifitas bagi para pelaku untuk mengembangkan bakat mereka sesuai dengan bidangnya masing masing dan dikenal oleh wisatawan dalam dan luar negeri serta menjadi tambahan pendapatan daerah yang nantinya akan mengangkat ekonomi mikro di Kabupaten Gresik, tentu tak terlepas dari tatanan masa, bentuk, dan ruang.

Demi mewujudkan tujuan rancangan dalam Bangunan gedung kreatif melalui tema dan konsep yang diusung, maka perlu diperhatikan pada permasalahan cara merancang dan selalu menggunakan tema Kontemporer dengan lebih spesifik penerapan pada tatanan masa, bentuk, dan ruang

\subsection{Arsitektur Kontemporer}

Arsitektur kontemporer merupakan suatu bentuk karya arsitektur yang sedang terwujud di masa sekarang dan masa akan datang. Karya ini dibangun dalam satu decade terakhir dan cukup menggambarkan perkembangan arsitektur di Indonesia. Arsitektur kontemporer merupakan salah satu pendekatan dalam merancang secara global sehingga banyak ahli yang mengemukakan pendapat mengenai pengertian dari arsitektur kontemporer, di antaranya sebagai berikut :

a. Y. Sumalyo, Arsitektur Kontemporer Akhir Abad XIX dan Abad XX (1996) "Kontemporer adalah bentuk-bentuk aliran arsitektur yang tidak dapat dikelompokkan dalam suatu aliran arsitektur atau sebaliknya berbagai arsitektur tercakup di dalamnya".

b. L. Hilberseimer, Comtemporary Architects 2 (1964) "Arsitektur Kontemporer adalah suatu style aliran arsitektur terntentu pada eranya yang mencerminkan kebebasan berkarya sehingga menampilkan sesuatu yang berbeda, dan merupakan suatu aliran baru atau penggabungan dari beberapa gaya arsitektur lainya

\subsection{Representasi dan Representatif sebagai Terori dalam Perancangan Arsitektural}

Representasi adalah konstruksi sosial yang mengharuskan kita mengeksplorasi pembentukan makna tekstual dan menghendaki penyelidikan tentang cara dihasilkannya makna pada beragam konteks (Barker, 2004). Representasi dan makna budaya memiliki materialitas tertentu. Mereka melekat pada bunyi, prasasti, obyek, citra, buka, majalah, dan program televisi. Mereka diproduksi, ditampilkan, digunakan dan dipahami dalam konteks sosial tertentu.

Representasi, dalam KBBI dan menurut Kusuma (dalam Kurniati, 2015) merupakan sebuah kata benda yang menunjukkan perbuatan dari sesuatu hal (yang dalam hal ini berupa objek arsitektural) yang mewakili keberadaan suatu hal lainnya (yang dalam hal ini adalah seseorang atau sekelompok masyarakat di mana objek arsitektur tersebut berada). Dari pengertian tersebut, dapat dipahami bahwa terdapat dua kegiatan penting dalam sebuah praktek representasi, yaitu kegiatan mewakili dan kegiatan (merasa) terwakili.

Representasi adalah sebuah produksi konsep makna dalam pikiran melalui bahasa. Ini adalah hubungan antara konsep dan bahasa yang menggambarkan objek, orang, atau bahkan peristiwa yang nyata ke dalam objek, orang, maupun peristiwa fiksi (S. Hall \& University, 1997). Representasi berarti menggunakan bahasa untuk mengatakan sesuatu yang penuh arti, atau menggambarkan dunia yang penuh arti kepada orang lain.

Teori Representatif menurut Hall \& University (1997), meliputi lima hal yaitu:

a. (Language) Pemahaman utama dari teori representasi adalah penggunaan bahasa

b. (Meaningful) untuk menyampaikan sesuatu yang berarti kepada orang lain.

c. (Meaning) Representasi adalah bagian terpenting dari proses dimana arti diproduksi dan dipertukarkan antara anggota kelompok

d. (Culture) Diproduksi dan dipertukarkan antara anggota kelompok dalam sebuah kebudayaan 
e. (Concept) Representasi adalah mengartikan konsep yang ada di pikiran kita dengan menggunakan bahasa.

Representatif merupakan untuk mengkomunikasikan ide yang menunjukkan proses berpikir dan desain. Sebagai hasilnya, jika diterapkan dalam karya arsitektural, akan menjadikan hasil yang beragam. Sebagaimana yang perwujudan bangunan yang ruang dalamnya hendaknya representatif terhadap kondisi lingkungan di sekitarnya, secara spesifik terkait fungsi dan aktivitas dalam bangunan tersebut, dan dikomunikasikan dengan baik yang mana ada persamaan pemahaman antara si pengirim dan si penerima pesan (Kurniati, 2015; Setyowati, 2009). Representatif di sini dapat ditarik kaitannya erat dengan sejarah, budaya, topografi, iklim, dan faktor sosial (kemasyarakatan dan kondisi kehidupannya). Hal itu menyebabkan perbedaan yang beragam dalam perwujudan representatif pada karya arsitektur.

Representatif sebagai wakil dalam arsitektur apabila objeknya lebih dari satu dan dapat dilihat dan divisualisasikan secara langsung, serta dapat mewakili keseluruhan. Representatif sebagai image dalam arsitektur yang memberikan penjelasan kepada orang lain tanpa harus bertanya dan secara langsung dapat mengartikan arti dalam bangunan itu sendiri. Jadi, kita dapat mengkomunikasikan makna objek melalui bahasa kepada orang lain yang bisa mengerti dan memahami konvensi bahasa yang sama. Oleh karena itu, proses representasi tidak bisa lepas dari istilah realitas, bahasa, dan makna.

Perancangan Pusat Pengembangan Produk Kreatif di Menganti Kabupaten Gresik adalah area / tempat yang cocok untuk dibangunkannya gedung kreatiif karena mengingat Kabupaten Gresik terkenal akan sektor kreatif agar para pelaku kreatif tersebut memiliki wadah untuk menunjukkan kreatifitasnya yang nantinya akan dijual serta dijadikan tempat pameran benda-benda kreatif. Di mana nantinya area tersebut dikembangkan pada pemaksimalan dan penambahan fasilitas sesuai dengan kebutuhan yang diperlukan tempat tersebut agar berjalan secara maksimal. Tempat tersebut berada di Menganti Kabupaten Gresik.

\section{Metode Penelitian}

Metode yang digunakan untuk penelitian desain rancangan adalah Metode Deskriptif (Groat \& Wang, 2013). Metode ini memiliki tahap Studi Kasus Literatur dan Studi Kasus Lapangan terutama terkait Representasi dalam Arstektur dan Arsitektur Representatif yang dinilai dan dibandingkan, serta menjadikannya referensi untuk rencana pengembangan tersebut dan mampu memenuhi kebutuhan Fungsi, Estetika, Aspek Arsitektural, Aspek Struktur dan Aspek lainnya.

Metode penelitian berdasarkan pengumpulan data nya, menggunakan metode kualitatif (Creswell, 2014). Sumber data yang digunakan antara lain berupa:

a. Data Primer: Observasi Literatur (Bali Creative Industry, Bandung Digital Valley, Jakarta Creative Hub, Police Married Quarters Hongkong).

b. Data Sekunder: Literatur, Web dan Buku.

Data teks yang telah diperolah kemudian dianalisa dan dieksplorasi menggunakan informasi yang telah dikumpulkan, sehingga dapat mengungkap proses representasi pada karya arsitektur dan dilanjutkan dengan menggunakan bantuan teknik komunikasi dan penyajian arsitektural. 


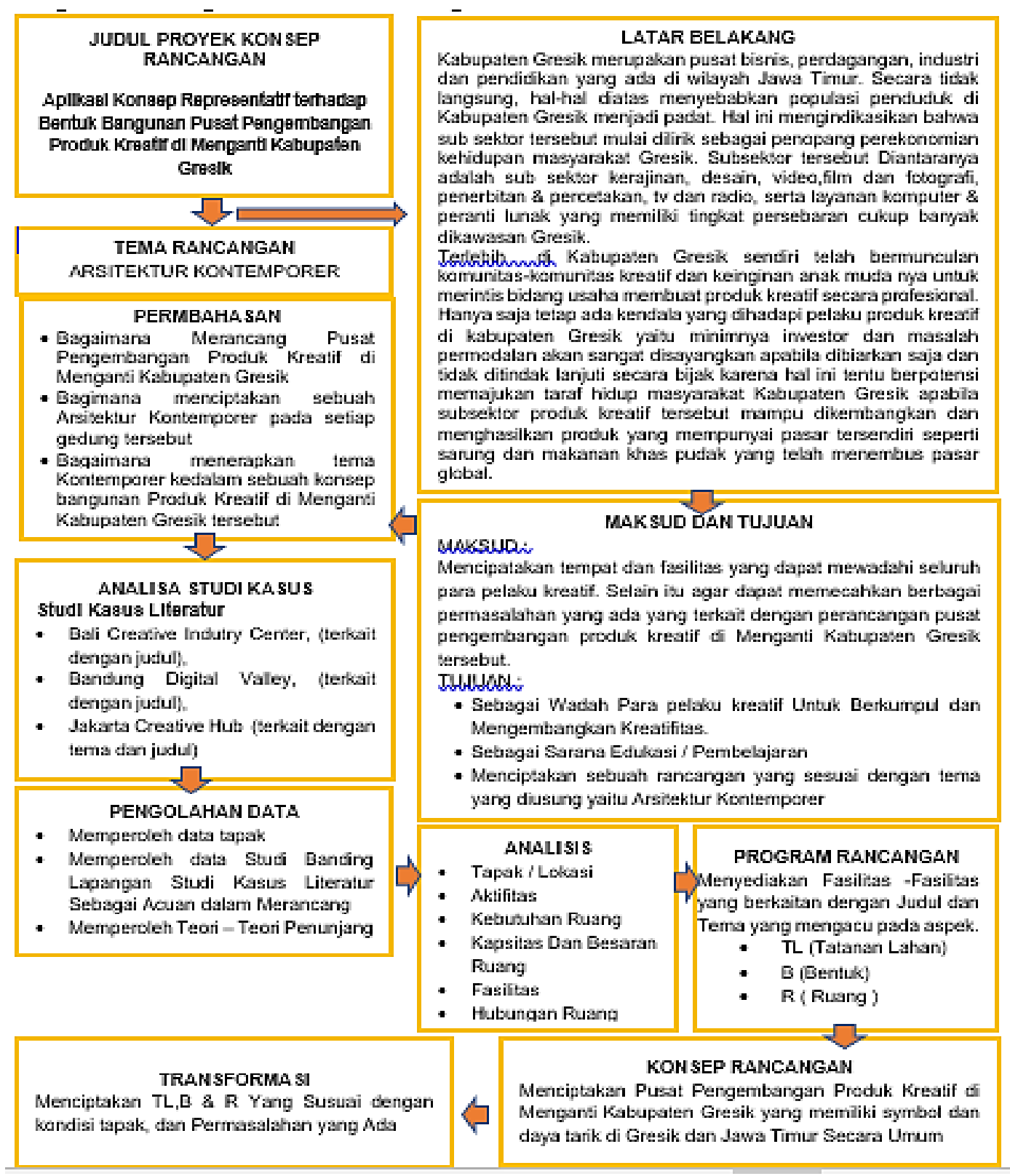

Gambar 1. Bagan Kerangka Berpikir Penelitian Kasus dan Deskriptif

\section{Analisa Lahan}

\subsection{Data Tapak dan Analisa Tapak secara Umum}

a. Tapak berada pada area pemukiman di Menganti Kabupaten Gresik

b. Analisa (Klimatogi matahari, hujan, angin dan kebisingan harus direspon dengan cara memberikan solusi pada desain misal, untuk mengurangi kebisingan maka di tambahkan vegetasi agar dapat di filter, untuk hujan maka disediakan saluran kawasan dan tampungan agar keluar pada saluran akhir (Kali Lamong) dalam keadaan layak buang.

\subsection{Berkaitan dengan Tema}

a. Untuk vegetasi pembatas (barier) didominasi menggunakan tanaman peneduh dikarenakan tanaman peneduh dapat memfilter panas, debu, serta suara bising kendaraan yang masuk secara langsung kedalam site.

b. Pada penataan massa nantinya perletakan gedung pameran indoor dan pameran outdoor diletakkan di depan site agar pengunjung memiliki ketertarikan secara langsung terhadap site. 
c. Penataan sirkulasi pada area site menggunakan pola Sirkulasi grid namun dengan garis sirkulasi yang bebas (lengkung, miring, elips)

\section{Hasil dan Pembahasan}

Tatanan Lahan menggunakan konsep mikro "Efektif" di mana untuk penataan masa bangunan, penataan parkir dan penataan sirkulasi nantinya harus memudahkan pengguna fasilitas dan juga berkesinambungan dengan keadaan eksisting.

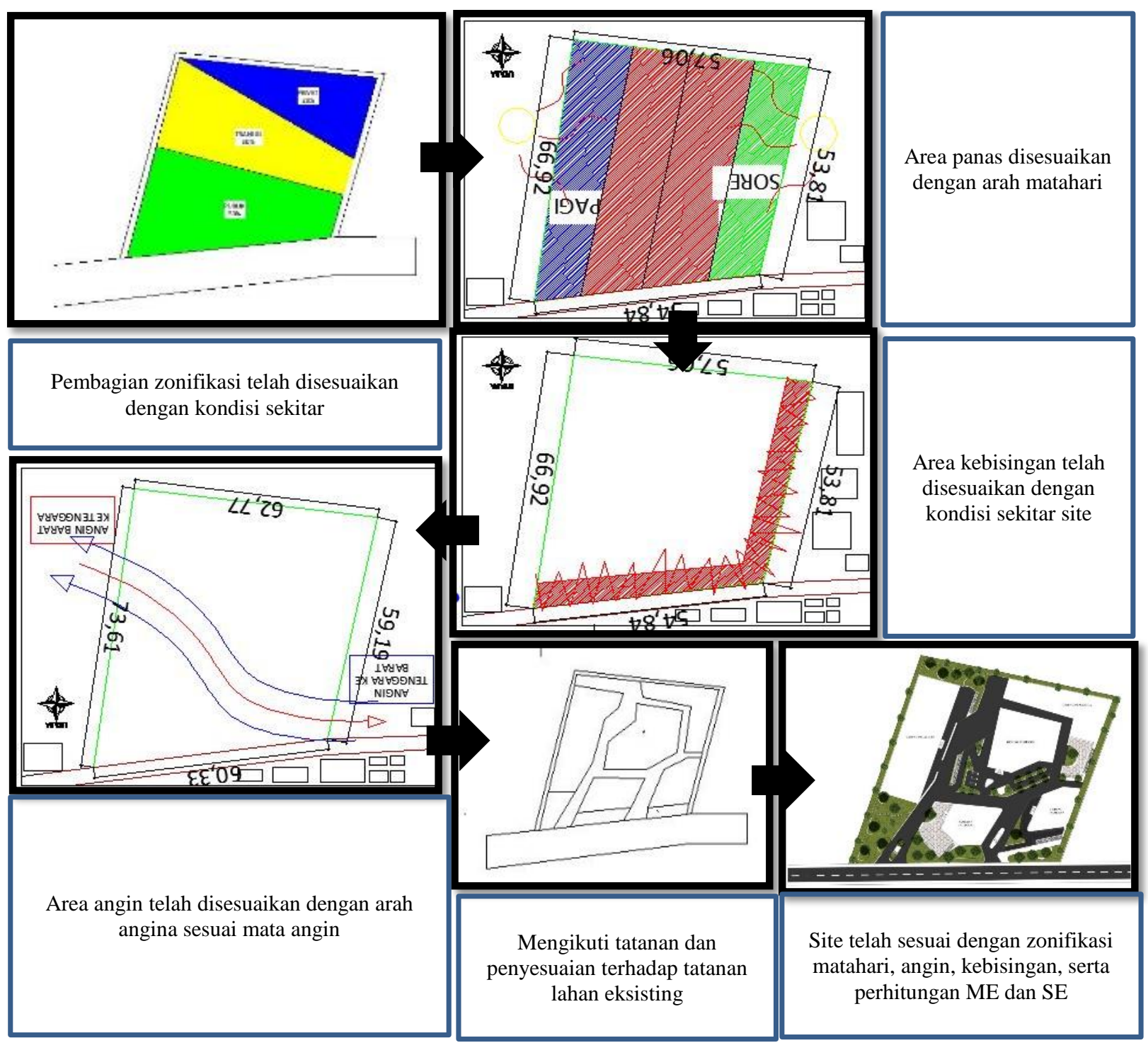

\section{Gambar 2. Transformasi Lahan}

Bentuk menggunakan konsep mikro "Ekspresif" di mana pembuatan bentuk bangunan dengan penggabungan unsur Konsep Ekspresif dengan Tema Arsitektur Kontemporer. Upaya mewujudkan tema dilakukan dengan adanya pemanfaatan lahan serta pemberian aksebilitas yang lengkap dengan perpaduan sirkulasi yang nyaman serta efisien melalui penataan yang bebas. 


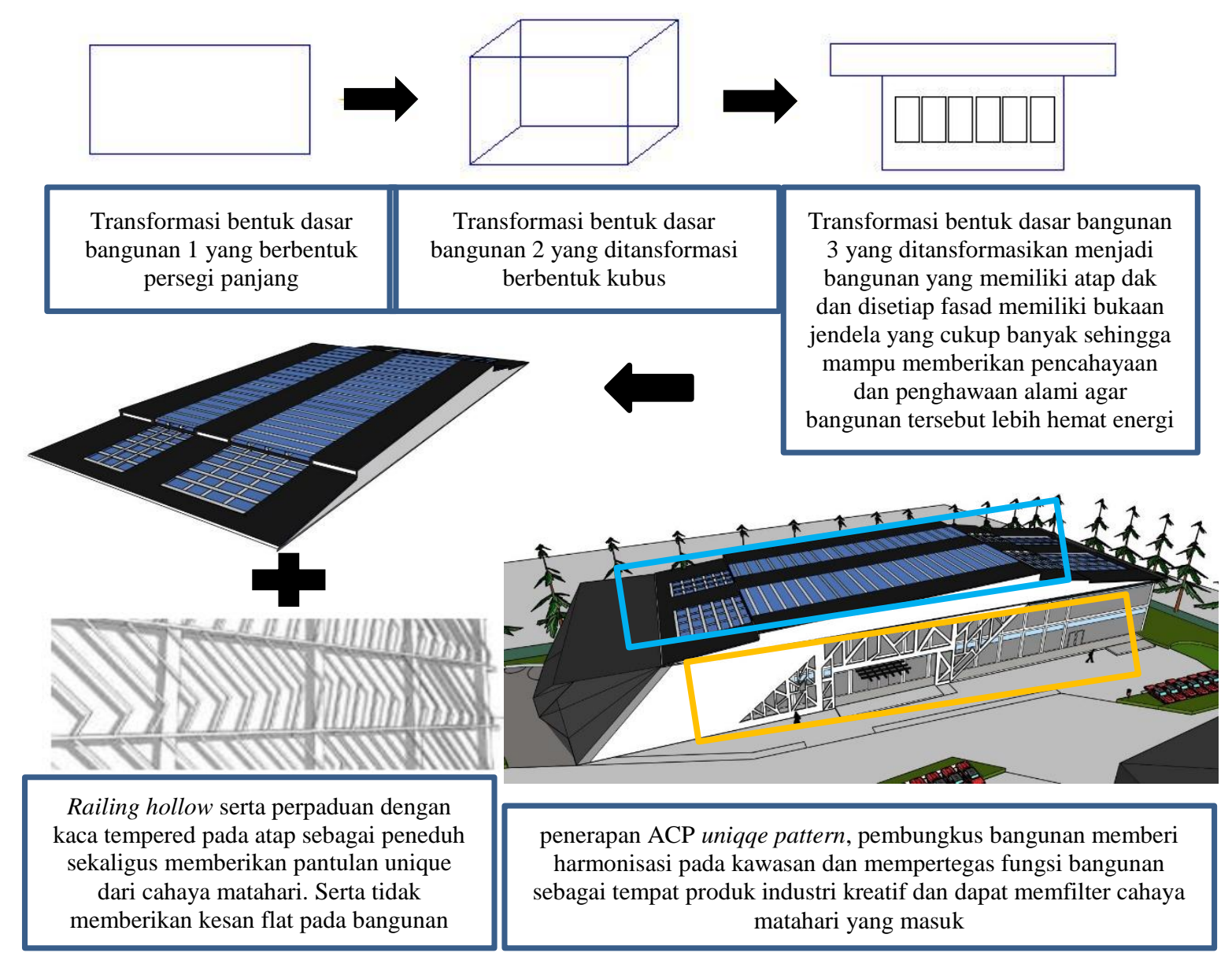

Gambar 3. Transformasi Bentuk

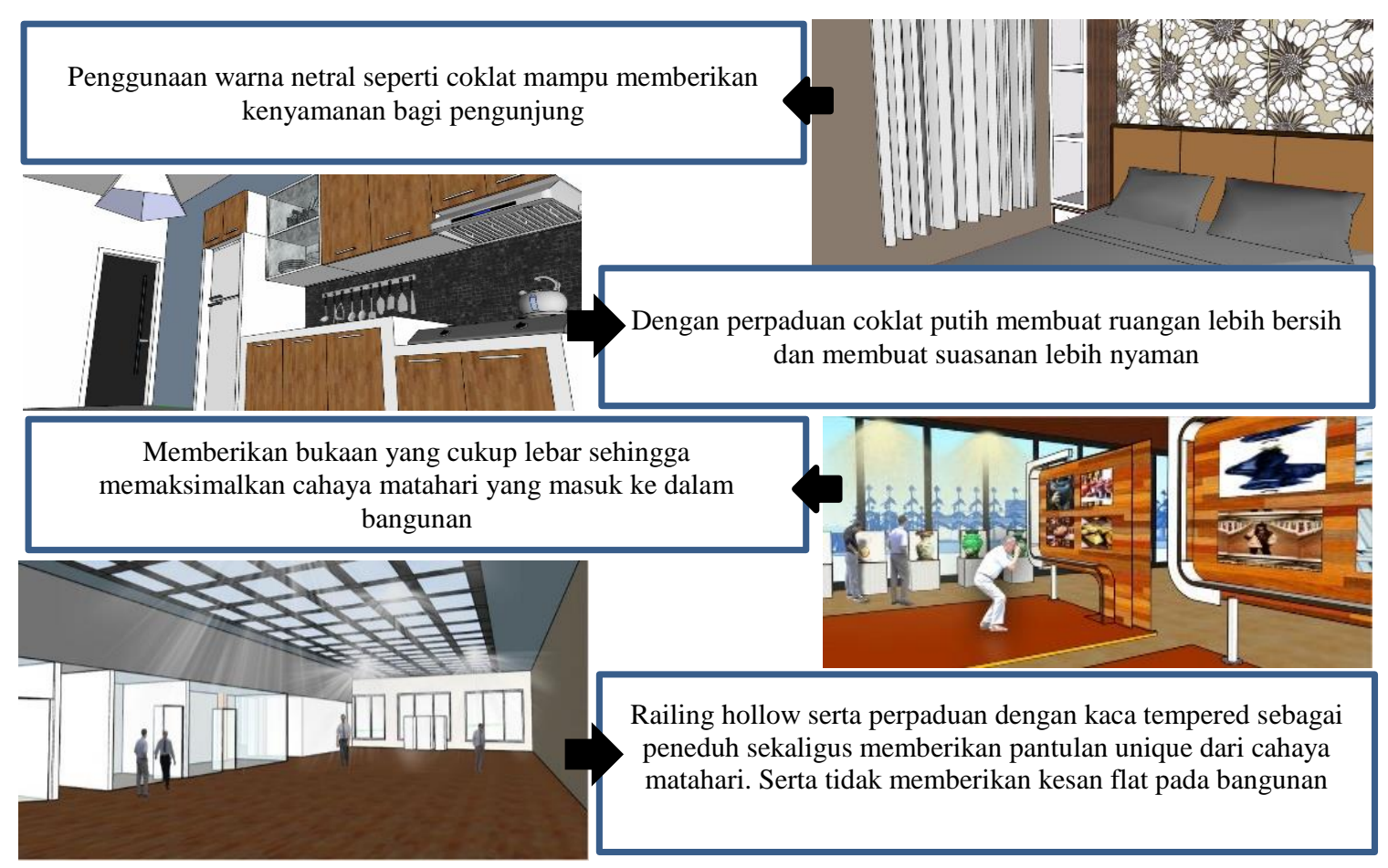

Gambar 4. Transformasi ruang 
Ruang menggunakan konsep mikro "Interaktif dan Fungsional" di mana dalam membuat memadukan Konsep Interaktif dan Fungsional dengan Tema Arsitektur Kontemporer. Sedangkan Konsep Makro Representatif bertujuan untuk menciptakan sebuah rancangan yang memiliki karateristik mudah di kenal dan dapat mengkomunikasikan ide desain. Oleh karena itu, representatif sebagai wakil dalam arsitektur apabila objeknya lebih dari satu dan dapat dilihat dan divisualisasikan secara langsung, serta dapat mewakili keseluruhan.

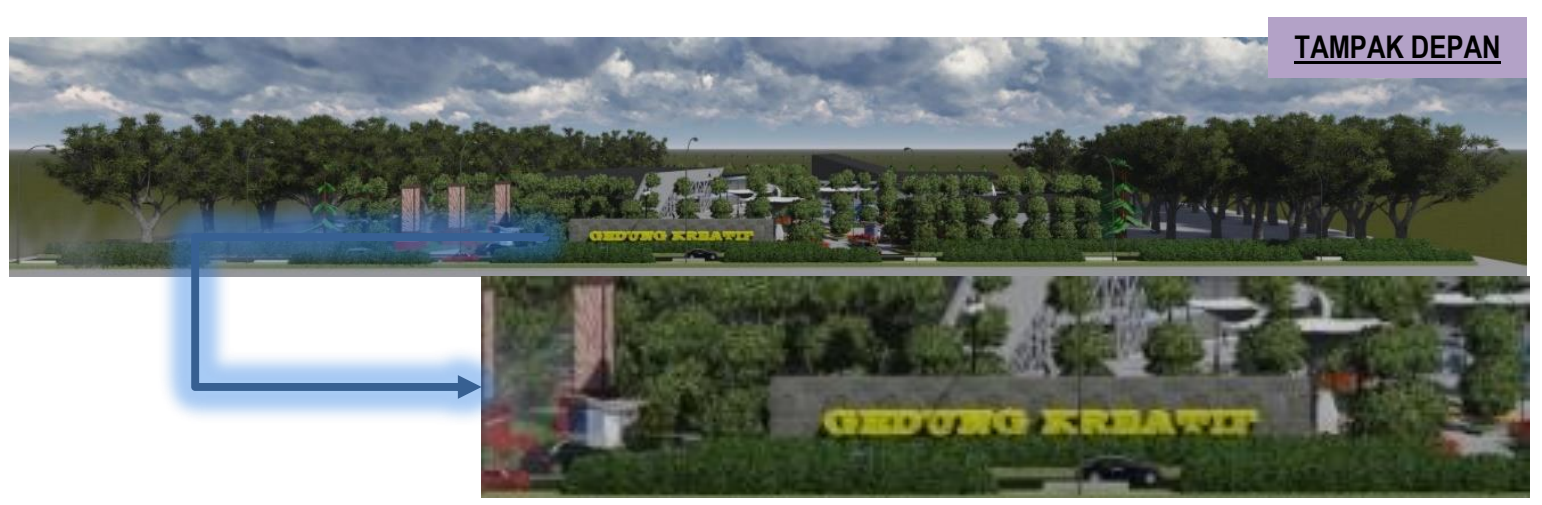

Gambar 5. Tampak depan

Pada tampak depan bangunan terdapat focal point pada bangunan yaitu nama gedung yang bertuliskan "Gedung Kreatif" yang diapit oleh main entrance dan side entrance pada site, sehingga pada saat orang beralu lalang didepan site mengerti kalua bangunan tersebut yaitu gedung kreatif
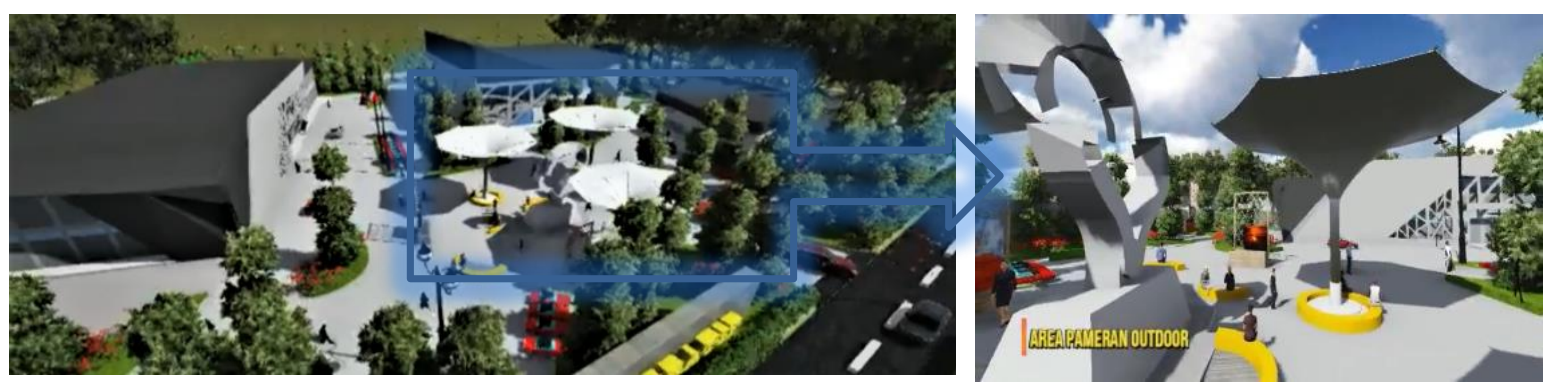

Gambar 6. Tampak Keseluruhan dan Area Pameran Outdoor

Pada site bagian depan juga terdapat pameran outdoor yang memamerkan hasil kreatifitasnya seperti lukisan dan hasil fotografi sehingga dapat dilihat dan divisualisasikan secara langsung, serta dapat mewakili keseluruhan jika bangunan itu adalah gedung kreatif. Representatif sebagai image dalam arsitektur yang memberikan penjelasan kepada orang lain tanpa harus bertanya dan secara langsung dapat mengartikan arti dalam bangunan itu sendiri.

\section{Kesimpulan}

Konsep makro pada objek tersebut adalah Representatif karena bertujuan untuk menciptakan sebuah rancangan yang memiliki karateristik mudah di kenal dan dapat mengkomunikasikan ide desain. Penerapan konsep makro representatif pada tatanan lahan yaitu sirkulasi dan penataan massa dengan mempertimbangkan eksisting yang berupa mengetahui kondisi fisik tapak, keadaan lingkungan pada tapak, batas-batas tapak, dan potensi yang ada pada tapak, Penerapan konsep makro representatif pada bentuk adalah penggabungan bentuk simetris pada fasad dan tumpukan pada atap. Penerapan konsep makro representatif pada ruang adalah penyesuaian dan penekanan unsur warna pastel dan unsur kayu. Manfaat dari Perancangan Objek ini yaitu agar Gresik memiliki sebuah wadah bagi para pelaku produksi 
kreatif untuk mengembangkan diri dan saling terhubung antara satu sama lain diantara sub sektor sub sektor produk-produk kreatif tersebut.

\section{Referensi}

Barker, C. (2004). The SAGE Dictionary of Cultural Studies. SAGE Publications Ltd.

Creswell, J. W. (2014). Research design : qualitative, quantitative, and mixed methods approaches (4th ed.). SAGE Publications, Inc.

Groat, L. N., \& Wang, D. (2013). Architectural Research Methods (2nd ed.). John Wiley and Sons.

Hall, S., \& University, O. (1997). Representation: Cultural Representations and Signifying Practices (Stuart Hall (ed.); Buku 2 dar). SAGE Publications, Inc. https://books.google.co.id/books?id=VsBdyhM9JEC\%7D,

Hilberseimer, L. (1964). Contemporary Architecture : Its Roots and Trends. Published by Paul Theobald $\&$ Co.

Kurniati, F. (2015). Representasi sebagai Bentuk Komunikasi dalam Arsitektur. TEMU ILMIAH IPLBI 2015, 4(Jurusan Arsitektur Universitas Sam Ratulangi Manado), E 178-190. TI2015-E-187-190Representasi sebagai Bentuk Komunikasi dalam Arsitektur

Setyowati, W. (2009). Teori, Metoda, dan Aplikasi Karya Arsitektur Tadao Ando. Jurnal Teknik Sipil Dan Perencanaan, 11(1), 81-92. https://doi.org/DOI: https://doi.org/10.15294/jtsp.v11i1.6969

Sumalyo, Y. (1996). Arsitektur Modern: Akhir Abad XIX dan Abad XX (Ke-2). 